\title{
Recent Developments in Nanomaterials for Geotechnical and Geoenvironmental Engineering
}

\author{
Mohd Raihan Taha \\ Institute for Environment and Development (LESTARI) \& \\ Dept of Civil \& Structural Engineering, \\ Universiti Kebangsaan Malaysia, Bandar Baru Bangi, Malaysia
}

\begin{abstract}
Nanotechnology has provided enormous benefits to the industrial and developed world. Most fields of knowledge have been tapping, using, and applying the advantages of nanotechnology to improve systems and living standards. This cannot be said for civil engineering and construction particularly geotechnical engineering. Actually, soil mechanics have been involved with nano scale dimensions and materials for a very long time, i.e. before the term nanotechnology and nanomaterials were coined. From the basic clay structure and the water molecules which give rise to soil plasticity/cohesiveness, geotechnical engineers were exposed to these phenomena since the early days of the subject. Currently, developments in nanotechnology and nanomaterials in geotechnical engineering has been limited to its use as an improvement and clean-up materials. Recent results have shown that the use of a small amount of nanomaterials ( $<1 \%$ of dry weight of the original soil) have resulted in significant change and improvement in soil properties. This is important since efficient use of materials is one of the facets of sustainability related to prolonging the life of our depleting natural resources. Experiences with nano-soil, nano-clay, nano-silica, nano-alumina, nano-magnesium, carbon nanotube and nanofibers, and nano-lime will all be discussed with respect to its use in soil improvement and soil remediation.
\end{abstract}

\section{Introduction}

Developments in nanotechnology particularly over the past 15 years has been fully tapped for its advantage by all fields of knowledge. The current state of disciplines such as electronics, manufacturing, medicine, energy, etc. would not have progressed much without nanotechnology. On the other hand, this cannot be much said for geotechnical engineering. However, geotechnical engineers are amongst the earliest "nanotechnologist" in which in the past they have dealt with materials at nano sizes and phenomenon that operates at nano scale [1].

One of the earliest related geotechnical publications was written by Bolt [2] who used the diffuse double layer to study the swelling pressures of clay. Since then these swelling pressure equations (Fig. 1) has been also used by a number of other researchers, notably by Sridharan \& Jayadeva [3], Komine \& Ogata [4] \& [5], Tripathy et al. [6], Tripathy \& Schanz [7], and Gurtug [8] to study clay behavior.

This purpose of this paper to provide some latest developments on 'nano' related research works in geotechnical and geoenvironmental engineering. Results

$$
\begin{aligned}
& p=2 \eta \kappa T(\cosh u-1) \\
& e=G \gamma_{w} S d \\
& \int_{z}^{u}(2 \cosh y-2 \cosh u)^{-(1 / 2)} d y=-\int_{0}^{d} d \xi=-K d \\
& \left(\frac{d y}{d \xi}\right)_{x=0}=\frac{B}{S} \sqrt{\frac{2 \pi}{\varepsilon \eta k T}}
\end{aligned}
$$

$p=$ repulsive force, $\eta=$ concentration of cation, $\kappa=$ Boltzman constant, $T=$ temperature, $e=$ void ratio, $G=$ specific gravity, $d=$ half distance of parallel platelets, $y=$ potential, $u=$ non dimensional mid plane potential, $z=$ non dimensional surface, potential, $K=1 / t_{d l}, t_{d l}=$ thickness of double layer, $x=$ the distance from the clay platelets.

Fig.1. Calculations of repulsive pressure from diffuse double layer theory [9]. 
on the use of nanomaterials such as carbon nanotubes, nanosoil, nanoclay, nanoalumina, etc. for soil improvement will be covered. This serve to show that nanoparticles are the latest generation of materials that can be used for soil treatment. As previously mentioned, geotechnical engineers as one of the major user of materials, should exploit this technology/material to our advantage and provide efficient use of materials for clients/society.

\section{Applications of Nanoparticles in Geotechnical and Geoenvironmental Engineering}

The use of nanoparticles for geotechnical engineering is still an emerging technology for possibly two fundamental reasons. The first issue is related to cost of the materials. It is generally felt that being nanomaterials, it must be expensive. Generally, the cost of nano materials, for example, carbon nanotubes are much less than it was a decade ago and still reducing due to increase in processing technology. Furthermore, in using nanomaterials, the recommended amount used is quite small, i.e. $0.1-0.5 \%$ of total weight of soil. The use is actually targeted at improving performance of geomaterials not replacing them. The second reason deals with toxicity. It is important to deal with this important subject because it is to be used in the field and directly exposed to the environment. On this concern, much studies have been conducted to evaluate toxicity on animals. While the results indicated that it has some negative impacts, many experts agree that the effects on human is still largely questionable. More studies are required, and safe with responsible use of materials can provide control and minimize risk to human and environment. Nevertheless, nanoparticles are currently already a constituent of much used items [10], for example, skin lotion, and this provide some evidence for supporting the use of nanoparticles against toxicity claims.

\section{Nano-Soil}

The nano-soil [11] was obtained by grinding a local soil (metasedimentary residual soil within the campus of Universiti Kebangsaan Malaysia, UKM). After the disturbed soil was dug and taken to the laboratory, it was first cleared of all roots and stones, dried in an oven, and sieved. Soil samples passing through $425 \mathrm{~mm}$ sieve was then pulverized in a planetary mono mill. In this mill, 20 small ( $5 \mathrm{~mm}$ diameter) balls made of sintered corundum move is a fast planetary/cyclonic fashion to pulverize the soil. The time of pulverization was about 10-13 hours in which during this period, distilled water was added to provide overheating. Fig. 2 show SEM images of the soil sample before and after milling. It can be clearly seen that there is much more soil in the nano range (i.e. 50-60 nm) in the soils after milling. The specific surface of the soil
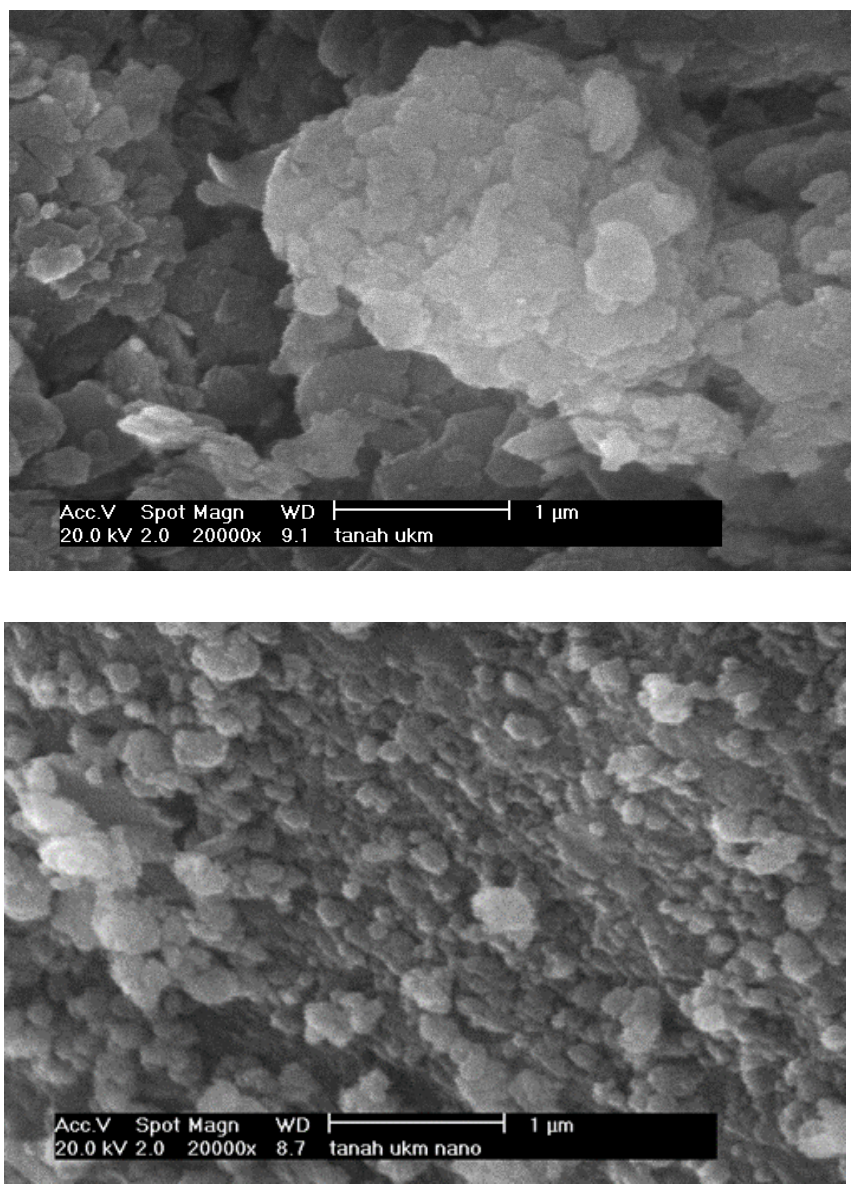

Fig. 2. SEM images of pulverized UKM soil before (top) and after (bottom) milling process.

obtained from EGME (ethylene glycol monoethyl ether) method improved from $2.4 \mathrm{~m}^{2} / \mathrm{g}$ to $3.9 \mathrm{~m}^{2} / \mathrm{g}$. Milling of kaolinite and montmorillonite samples show similar observations.

In order to evaluate its potential for improving soil properties, a soil-cement mix was prepared and the nanosoil was added to the mix. The amount of nano-soil added was 1 and $2 \&$ by weight of the UKM soil. Thus, the overall mixture is $94 \%$ UKM original soil, $6 \%$ Portland cement, and nano-soil. The results of compression test on $50 \mathrm{~mm}^{3}$ samples are shown in Fig. 3 [12]. The results in Fig. 9 show significant improvement in the strength of the nano-soil mixtures over the control test albeit the amount of nano soil added was rather quite low. The strength of the soil-cement mixture almost doubled when $1 \%$ UKM nano-soil was added compared to samples without nano-soil. In addition, the mixture which is usually termed as cement-modified soil in geotechnical engineering will have lower tendency of volume change and PI in addition to increase in load bearing capacity. This study has demonstrated that even a small addition of nanoparticles will show marked enhancement in soil behavior. It is also possible to engineer nanoparticles to improve behavior of soils to suit design and practice requirements. 


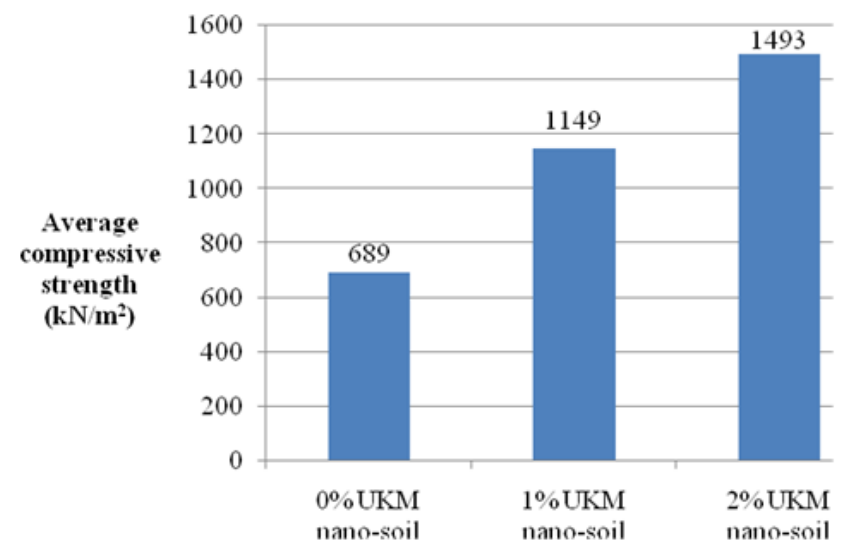

Fig. 3. Compressive strength of soil-cement and nano-soil mix.

\section{Carbon Nanotube (CNT)}

Carbon nanotube is considered as the first generation nanomaterial in that it is one of the earliest nanoparticles that was produced. Carbon nanotube is so popular and interesting because it has many "super" properties, especially for those working in electronics and superconducting industries. It has high unparalleled strength, high electrical and thermal conductivities, making it ideal for wide range applications [13] \& [14]. Thus, it is sometime termed as the "king of nanomaterial" and also "a solution waiting for problem". Interestingly (at least for geotechnical engineers). It resembles a clay mineral, halloysite, which is in the same group as kaolinite, resembles the tubular CNT shape (Fig. 4).

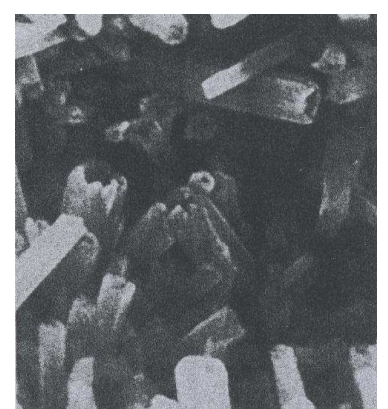

(a)

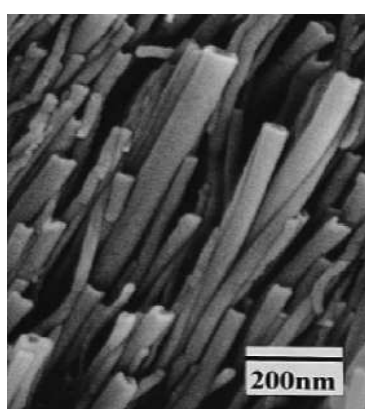

(b)
Fig. 4. (a) Electron photomicrograph of halloysite [5]; and (b) SEM of MWNT (multiwalled nanotube, a type of CNT) [15].

Earlier study has shown that even with small amount of CNT (in the form of multiwalled nanotube from Arkema, France), the changes in basic characteristics are measurable $[\mathrm{X}]$. Increase in CNT led to increase in LL, PL and plasticity index (PI=LL-PL). In these tests, the addition of the fine CNT particles certainly increases the overall specific surface of the mixture. As a result, the need for water, is greater and thus this is indirectly shown by an increase in LL. The increase in PI is due to the fact that the increase in PL is not as dramatic as the increase in LL. It was also found that the values of $G_{s}$, in general, also decreases upon addition of CNT due to the low density of CNT.

These results have important significance in geotechnical engineering. In terms of mechanical properties, increase in LL (and increase in surface area) means the soil will have higher capacity for water thus decreasing its strength and increasing its consolidation/compressibility (settlement). However, increase in PI will generally mean a decrease in its hydraulic conductivity. For geotechnical structures (such as foundations and retaining walls) in which strength and compressibility are the main criteria, the use of CNT may not be advantageous. In the case of landfill liners and caps, in which low hydraulic conductivity is very important, its use may thus be considered.

The use of unenhanced CNT was also attempted to adsorb contaminants from the subsurface for application as barrier or filter materials. CNT was used as a remediation material to adsorb DDT from solution. A maximum of almost $90 \%$ adsorption can be achieved (Fig. 5). The relatively high adsorption is due to action of the CNT in which it acts as a sponge due to the strong adsorption forces inside in CNT. Also, because of its small size, the CNT capture and retain small molecules in their interior. Their sorption energy and sorption energy are much higher than that of activated carbon.

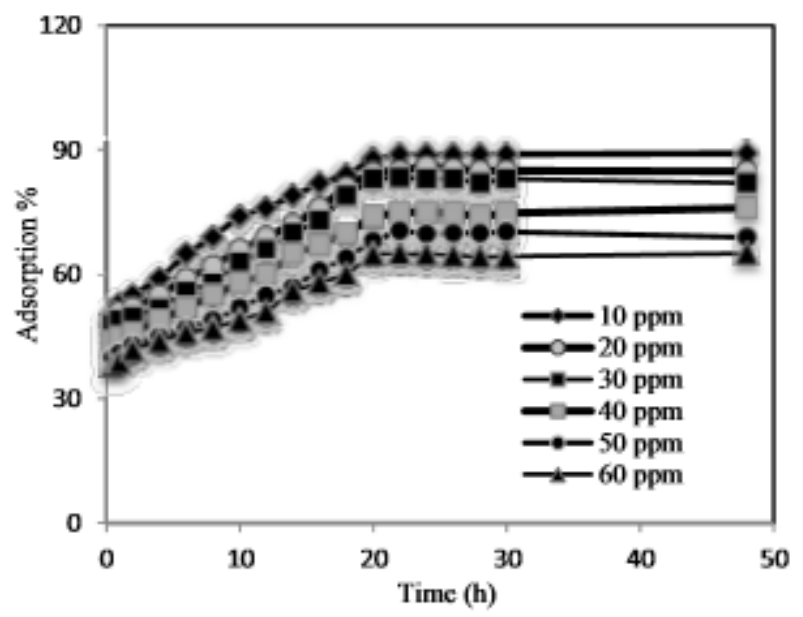

Fig. 5. Adsorption of DDT in various solution by CNT [16]

It must be emphasized that the hydrophobicity and clogging of CNT presents the greatest challenge in mixing soil with CNT. The two test results presented above could be improved if the CNT could be well mixed with the soil. Attempt to mix the soil by sonication have yielded an excellent dispersion of CNT and carbon nanofibers $(\mathrm{CNF})$ within the particles, contributing to bridging effects, which transfer loads across the nanoand micro-cracks.

\section{Nano-Clay}

Volume change of a compacted residual soil (UKM metasedimentary residual soil) was studied using a natural montmorillonite. The nano-clay material was supplied by Southern Clay Products Inc, Gonzales, Texas, USA under the product name Cloisite ${ }^{\circledR N a}{ }^{+}$. Fig. 6 shows the effect of nanoclay on the expansive, shrinkage 
and total strains. The shrinkage strain slightly decreased at $0.05 \%, 0.1 \%$, and $0.15 \%$ then increase while there was no increased in expansive strain at the these nano-clay content. However, when as the amount of nanoclay is increased, the expansive and shrinkage strain increases leading also to the total volume change increase. The total shrinkage strain after saturation was measured relative to the final volume of sample when become fully dry. The total shrinkage strain is the total volume change and approximately equal to the shrinkage volume change and expansive volume change. The increase in nanoclay more than $0.3 \%$ gives a clear increase in total volume change [17].

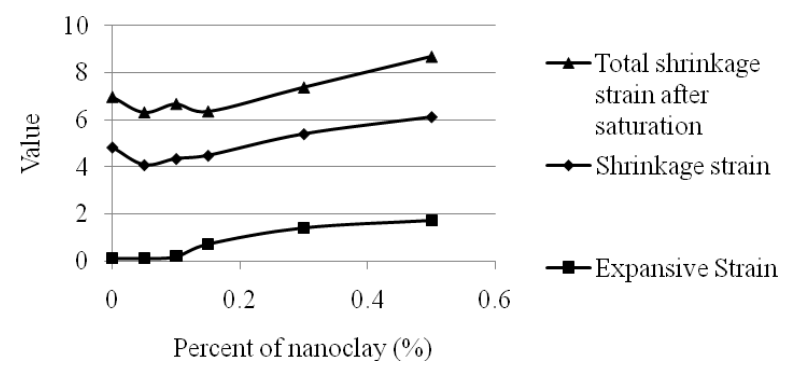

Fig. 6. Influence of nano-clay on the expansive, shrinkage and total strains

Nano-clay gives a noticeable decrease in hydraulic conductivity due to increase in the smaller size of particles. The nanoclay particles probably diffused between the large sedimentary soil particles, closing or minimizing the pores which lead to a decrease in the flow of water in the soil mixtures. This is a very significant results because one of the common materials tested to reduce the shrinkage strain is fiber. Mixing the soil with fiber can reduce the shrinkage strain up to $90 \%$ but the fiber caused an increase in the hydraulic conductivity up to 50 times [18]. Thus using nano-clay will improve volume change behavior and at the same time lowering the hydraulic conductivity of soil.

\section{Nano-Alumina}

Nano-alumina was used to study crack intensity factor (CIF) which is important to assess crack formations around waste containment systems. The nanoalumina was purchased from Inframat Advanced Materials, Manchester, CT, USA. It has a chemical formula $\mathrm{Al}_{2} \mathrm{O}_{3}$, particle density of $3.6 \mathrm{~g} / \mathrm{cm}^{3}$, surface area of $>150 \mathrm{~m}^{2} / \mathrm{g}$, and a transitional gamma crystal structure [19]. For high plasticity soils (given as S3 and S4 with plasticity index of 18 and 69 , respectively), the CIF is minimum at $0.1 \%$ nano-alumina content (Fig. 7). Furthermore, the hydraulic conductivity measurements showed that adding nano-alumina will cause a slight decrease in its value which is always a favorable characteristic for landfill liners and caps. Thus, using nano-alumina for desiccation crack control does not cause detrimental effects on the hydraulic behavior of the soil.

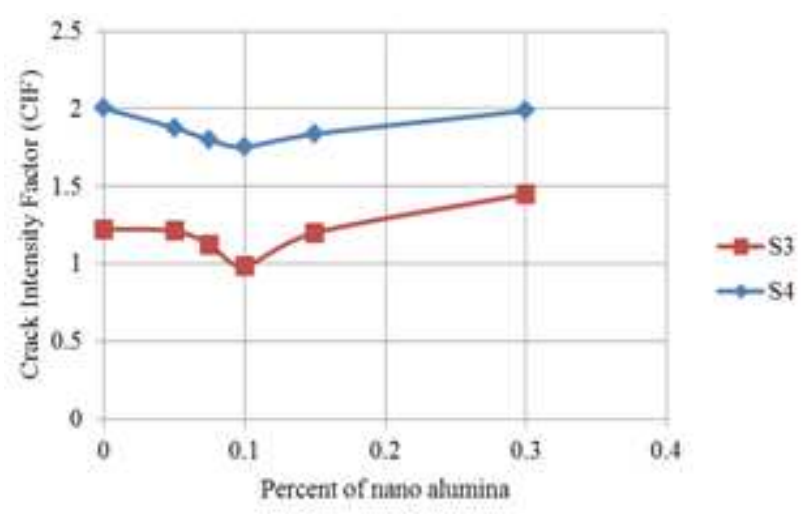

Fig. 7. Effect of nano-alumina on crack intensity factor.

\section{Nano-Lime}

Lime is a well-established soil stabilization material. The use of nano-lime is possibly aimed at overcoming some of the limitations of traditional limebased materials, such as the difficulty in achieving a complete carbonation, while maintaining their advantages [20]. Nano-lime powder was imported from Strem Chemicals, Inc., Mulliken Way, Newburyport, Massachusetts, United States. Results in Fig.8 indicated that only about $0.3-0.5 \%$ nano-lime is required to achieve UCS strength much higher that without nano-lime. In addition, nano-lime induced noticeable increase in UCS of soil-nano-lime mixtures; that is, the strength of the mixtures with nano-lime was higher than the strength of mixtures with lime. These may be due to higher ability of nano-lime to flocculate and agglomerate the soil particles compared with the lime. Agglomeration and flocculation occurred with the availability of $\mathrm{Ca}^{+2}$ cations. Ions exchange mechanism possibly took place between monovalent ions $\left(\mathrm{Ca}^{+2}\right)$ with divalent $\left(\mathrm{Na}^{+}, \mathrm{H}^{+}\right)$ions leading to reduction of repulsion forces and bridging the clayey particles of negative surface ions. This may again be related to the reactivity of nano-lime and its ability to release more $\mathrm{Ca}^{+2}$ ions than lime. This is supported with the purity of nano-lime which is higher than the lime [21].

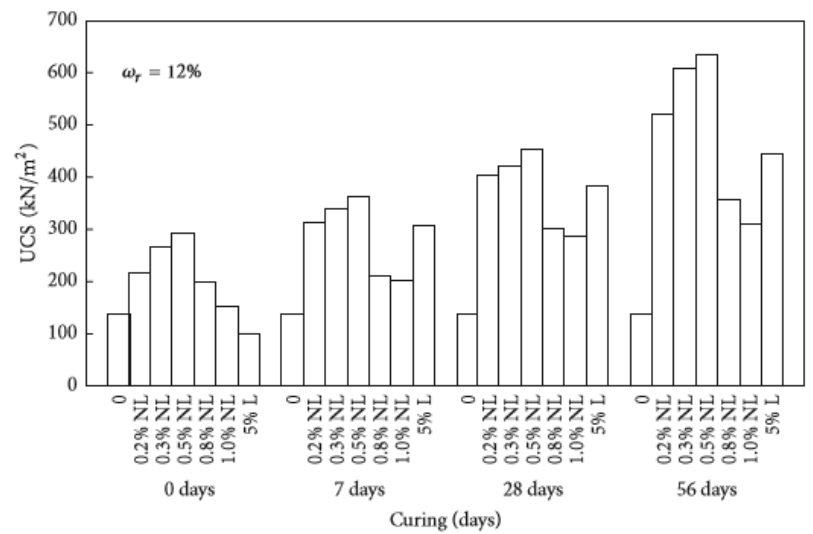

Fig. 8. UCS of soil-nano-lime and soil-lime mixes. 


\section{Other Nanomaterials}

Nano-copper and nano-magnesium are other materials that have been tested to improve the properties of soil [22] [23]. The results are almost similar to most of the studies above in which there is an optimum amount of nanomaterials after which adding more nanomaterials will cause adverse effect to soil properties. These optimum amount normally occurs at less than $1 \%$ of the weight of the soil used.

\section{Conclusion}

In this presentation, laboratory results from work done at Universiti Kebangsaan Malaysia (UKM) on the application of nanomaterials for soil improvements is presented. From the results obtained, it is shown that nanomaterials are potential materials to be innovatively used for enhancement of soil properties. For example, fibers are normally used to improve shrinkage in soils. However, while greatly reducing the shrinkage strain, fibers also significantly increases the hydraulic conductivity of soils. This is where nanomaterials such as nano-clay and nano-alumina becomes handy. The use of these materials will reduce soil shrinkage and at the same time reducing the hydraulic conductivity suitable for waste containment systems. In addition, nanomaterials such as nano-soil and nano-lime significantly increase the compressive strength soil-cement and original soil-lime mix. It can be expected that with time and developments in nanotechnology, more nanomaterials will be produced providing geotechnical and geoenvironmental engineers more options to improve the properties of soils.

\section{References}

1. M.R. Taha, E. Ismail, Z. Chik. $2^{\text {nd }}$ Intl Symp on Nanotechnology in Construction, pp. 373-381 (2005).

2. G.H. Bolt, Geotechnique 6(2), pp. 86-93 (1956).

3. A. Sridharan, M.S. Jayadeva, Geotechnique 32(2), pp. 133-144 (1982).

4. H. Komine, N. Ogata. Canadian Geotech J. 33(1), pp. 11-22 (1996).

5. H. Komine, N. Ogata. Canadian Geotech J. 40(2), pp. 460-475 (2003).

6. S. Tripathy, A. Sridharan, T. Schanz, Canadian Geotech. J. 41(3), pp. 437-450 (2004).

7. S. Tripathy, T. Schanz, Canadian Geotech. J. 44(3), pp. 355-362 (2007).

8. Y. Gurtug, Applied Clay Science 51, pp. 295-299 (2011)

9. A. Sridharan, Chemo-Mechanical Coupling in Clays: From Nano-Scale to Engineering Applications, pp.128 (2002).

10. M.R. Taha, Nanomaterials and Geotechnical Engineering: Big Problems Small Solution (in Malay). Inaugural Lecture (2012).
11. M.R. Taha, S.Y. Lim, Z. Chik. Jurnal Kejuruteraan, UKM, 21, pp.1-10 (2009).

12. M.R. Taha, Nanotechnology in Construction, Proc NICOM3, pp. 377-382 (2009).

13. G.A. Ozin, A.C. Arsenault, Nanochemistry: A Chemical Approach to Nanomaterials (2005).

14. W. Marx, A. Barth, Carbon Nanotube, pp. 1-18 (2010).

15. K. McGuire, A.M. Rao, Carbon Nanotubes Science and Applications, pp. 117-136 (2005).

16. M.R. Taha, S. Mobasser, PLoSONE 10(12), pp. 1-16 (2015).

17. O.M.E. Taha, M.R. Taha, Proc $5^{\text {th }}$ Jordanian International Civil Engineering Conference, pp. 417423 (2012).

18. S.M. Rifai, $P h D$ Dissertation, Wayne State University, USA (2000).

19. M.R. Taha, O.M.E. Taha, NICOM4-Nanotechnlogy in Construction-4 Intl. Symposium, pp. 1-9 (2012).

20. V. Daniele, G. Taglieri, R. Quaresima, Journal Cultural Heritage, 9(3), pp. 294-301 (2008).

21. P. Govindasamy, M.R. Taha, J. Alsharef, K. Ramalingam, Applied and Environmental Soil Science, Article 8307493, 9 pages (2017).

22. M.R. Taha, O.M.E. Taha, J Nanopart Res, 14 :1190 (2012).

23. Z.H. Majeed, M.R. Taha, I.T. Jawad, Research Journal of Applied Sciences, Engineering and Technology, 8(4), pp 503-509 (2014). 